\title{
educação

\section{A Educação Nova e o Novismo em Educação: O novo como ilusão necessária}

\author{
Alberto Filipe Ribeiro de Abreu Araúuot \\ Universidade do Minho, Portugal \\ Joaquim Machado de AraújoII \\ Universidade Católica Portuguesa, Portugal
}

\begin{abstract}
Este artigo assinala as vertentes utópica e ideológica da visão educativa da Educação Nova. Distingue uma perspetiva do totalmente novo fechado sobre si próprio, que se absolutiza e visa instaurar um mundo totalmente outro, e uma perspetiva do novo relativo, que reconhece as partes da novidade que estão "aí" à espera de uma formulação sistemática que as acolha e lhes dê o sentido de um todo. Um todo sempre não completo e, por isso, inconfundível com o campo da experiência e aberto a outras partes da novidade de que o todo possa carecer, mesmo que o ignore. Discorre também analítica e criticamente sobre a natureza do "novo" que a "novidade" da Educação Nova seria suposto veicular, e indaga se ele não é mais uma ilusão provocada pela crença e pelo desejo dos fundadores da Educação Nova do que, na verdade, um facto substantivo e radicalmente inovador como eles o pretendiam fazer crer. Por fim, considera as trocas mútuas da ideologia e da utopia enquanto figuras da imaginação e, reconhecendo a incorporação de partes do Novo na Escola Tradicional, identifica o impoder da Educação Nova e reafirma o Novo como ilusão necessária a um movimento de renovação pedagógica.
\end{abstract}

Palavras-chave: Esperança; Educação Nova; Escola Tradicional; Rutura

\section{N T R O D U Ç Ã O}

A Educação Nova atinge o seu ponto alto entre a primeira (1914-18) e a segunda (19391945) Guerras Mundiais e, nesse sentido, corresponde a um movimento situado num tempo histórico concreto, carecendo de afirmar a sua novidade por contraposição à escola existente - a Escola Tradicional - e de garantir que apenas nela residia um futuro de paz, porque apenas por ela se renovaria a escola, se formaria o "homem novo" e se instituiria a "nova era" de que a sociedade precisava.

Este artigo identifica as principais características da proposta de "escola nova" apresentada pelos principais autores da Educação Nova para instituir essa "era nova", assinalando quer as críticas deste movimento de renovação pedagógica à Escola Tradicional quer as distintas ruturas pedagógicas que 
o antecedem e que estão na base da sua defesa de uma pedagogia mais ativa e mais congruente com os contributos dados, sobretudo da psicologia, então emergente como área científica. Procede também a uma análise crítica sobre a natureza do "novo" deste movimento e, ancorando-se numa perspetiva que distingue o novo absoluto e o novo relativo e considera a ideologia e a utopia como figuras da imaginação, reconhece nestas trocas mútuas partes do "novo" da Escola Nova que vieram a ser incorporados pela Escola Tradicional. Ao mesmo tempo, assinala o (im)poder da Educação Nova para ocupar todo espaço pedagógico, destacando o Novo como ilusão necessária a um movimento de renovação pedagógica.

\section{O NOVO COMO RUTURA E CONTINUIDADE}

A abertura do ser humano ao Novo radica na carência de algo, recebe o seu impulso da existência de um vazio e da necessidade de o preencher. Explica Ernst Bloch (1977) que o Novo alimenta a esperança que a utopia transporta e sugere a rutura com uma realidade que aprisiona e que favorece a desesperança. Faz parte da genética da Utopia, por contraposição à ideologia, apontar para o "novo" a vir, para a "novidade", para "novas alternativas", e ser esperançosa, criativa, abrir novos caminhos ao mundo existente e às ideias que o legitimam. É isso mesmo que a Educação Nova proclama e pretende ser: ser (não uma, mas) a alternativa à Escola Tradicional (que Adolphe Ferrière apresenta como Escola do Diabo), a única alternativa realmente portadora de novidade e de esperança em tempos melhores, na vinda de "novos tempos", a única capaz de criar dinâmicas prenhes de novidade... Em tempos de necessidade de rutura, o discurso pedagógico altera precisamente o jogo de luz e de sombra, colocando a luz no tempo a vir e na proposta pedagógica a instituir e projeta a sombra sobre o passado que se quer expurgar, bem como as sombras na pedagogia instituída (Baczko, 1980, p. 95).

O totalmente Novo advém de uma perspetiva radical, e esta fecha-se sobre si própria e revestese dos temas míticos do "prestígio das origens" e do "fim" que alimentam a faceta milenarista de justiça e de paz eternas, a esperança de um "mundo novo" e de um "homem novo" (Araújo, 1997, p. 138). Este "halo cósmico" é sugerido, por exemplo, por Maria Montessori $(1936,1996)$ quando desenvolve a conceção de criança-progenitor, a criança como progenitor e mestre do "homem novo" a formar, o "homem integral" necessário para realizar uma "nova era", uma era de harmonia e de paz. Ao mesmo tempo, o recurso sistemático à metáfora agrícola, a conceção da criançaplanta e do educador-jardineiro sugerem uma ideia de continuidade, agora remetida para a natureza e para a necessidade de a respeitar, legitimando assim a perspetiva de regeneração necessária à recuperação da paz edénica que a própria rutura operada pela Educação Nova anuncia consubstanciada numa "nova era" povoada de "homens novos".

Um olhar mais aberto sobre o Novo tem consciência da evidência de continuidades e ruturas nos fenómenos sociais, como mostram os estudos das revoluções quando encarados em termos de longa duração. Consequentemente, esse olhar mais aberto afirma a novidade que anuncia, mas reconhece as ruturas que a precedem e que ela mesma incorpora e abre-se à sua própria regeneração, mesmo que, no momento, desconheça a(s) parte(s) de novidade de que carece para se completar. É, evidentemente, o caso de Édouard Claparède (1916, pp. 41-100), que coloca a génese da rutura na "revolução copernicana” operada por Rousseau, assume a consideração da criança, da sua natureza 
e dos seus "interesses" e, por isso, desloca o centro dos processos educativos, que antes era colocado no professor (magistrocentrismo), para a criança (puerocentrismo). E deste novo centro emerge uma pedagogia nova e uma escola nova, a escola ativa. Neste aspeto, a utopia é atenuada por aquilo que Paul Ricoeur (s/d) designa de "o credível disponível de uma época”, isto é, pela reflexão de carácter prático e político que a Educação Nova pode encontrar na pedagogia vigente e no pensamento pedagógico acumulado e "manter aberto o campo do possível” do não-lugar que anuncia (pp. 383-384).

A utopia da Educação Nova pensa, pois, um "modo diferente de ser" do educativo e apresenta-o como o invés do mundo existente, porque este é percebido como imagem invertida da realidade da natureza da criança, e insurge-se contra a pedagogia da Escola Tradicional no que ela preserva e conserva dessa realidade que está distorcida e que a ciência emergente (a psicologia) não legitima. Como escreve Ferrière (1934a), embora já diversos pedagogos tivessem como ideal da escola "a actividade espontânea, pessoal e produtiva” (p. 6), a sua intuição "prolonga-se e enriquece-se com o conhecimento psicológico do espírito da criança e das leis do seu crescimento" (p. 6).

De facto, é o conhecimento da criança proporcionado pelas descobertas da psicologia, da fisiologia e da medicina (Ferrière, 1934b, p. 17) que impulsiona os esforços de construção de uma pedagogia "experimental" (Claparède, 1916) ou "científica” (Montessori, 1932) e a expectativa de uma "educação funcional" (Claparède, 1933) e de uma "escola por medida" (Claparède, 1953). Segundo Ferrière (1934b), estas descobertas exigem a consideração de uma "quádrupla constelação": a) o respeito pelas etapas de desenvolvimento da criança; b) as necessidades sociais da época; c) as necessidades e aptidões do educador (o "molde do professor"); e d) "os recursos de que a ciência e a prática pedagógica contemporâneas dispõem para favorecer o desabrochar das aptidões do educador e lhe permitirem uma colheita de frutos benéficos: métodos Montessori, Decroly, Dewey, Parkhurst, Washburne, etc." (p. 145).

\section{As CRÍtICAS À ESCOLA TRA DICIONAL}

Os pedagogos da Educação Nova sempre procuraram exagerar, mesmo caricaturar, os seus comentários, críticas e desenvolvimentos sobre a Escola Tradicional com o objetivo, certamente, de melhor realçarem a sua missão de "transformadores" do antigo ou, se se preferir, de anunciadores de uma "novidade" pretensamente salvífica. A este respeito, vejamos o livro-manifesto de Adolphe Ferrière (1928), intitulado Transformemos a Escola, onde o autor, de forma paradigmática, apresenta a escola como se fosse uma invenção do Diabo:

A criança adora a natureza: encerraram-na dentro de casas. A criança gosta de brincar: obrigamna a 'trabalhar'. Pretende saber se a sua atividade serve para qualquer coisa: fez-se com que a sua atividade não tivesse nenhum fim. Gosta de mexerse: condenam-na à imobilidade. Gosta de palpar objetos: ei-la em contacto com ideias. Quer servirse das mãos: é o cérebro que [a Escola Tradicional] lhe põe em jogo. Gosta de falar: impõe-lhe silêncio. Quer esmiuçar as coisas: constrangem-na a exercícios de memória. Pretende buscar a ciência de motu proprio: é-lhe servida já feita. Desejaria seguir a sua fantasia: fazem-na vergar sob o jugo do adulto. Quereria entusiasmar-se: inventaram-se os castigos. Quereria servir livremente: ensinouse-lhe a obedecer passivamente. $\mathrm{O}$ diabo ria pela calada! (p. 12) 
Adolphe Ferrière (1928) continuou a denunciar os efeitos perniciosos da escola, em que uma das consequências visíveis foi obrigar a criança a adaptar-se a condições de uma vida artificial acabando por estiolar, tornar-se passiva e apática. A escola do Diabo contribuiu para que a felicidade e a saúde das crianças desaparecessem: "Não mais saúde, felicidade, amor, beleza. Como o espírito, a alma tornouse seca e pardacenta. O ódio fez nela germinar cardos. E para essa gente, Deus deixou de existir, a coisa é evidente. Deus apenas reside nas almas sãs" (Ferrière, 1928, p. 15). Já num outro capítulo, dedicado às "responsabilidades", o autor aconselha a leitura de biografias de grandes homens, nas quais se pode descobrir que "quase sempre, por um ou outro motivo, eles se esquivaram outrora à escola" (p. 19). Refere também um livro de testemunhos sobre as recordações, boas ou más, da escola onde se pode ler a resposta daqueles que, apesar da escola, conservaram a frescura e a energia de espírito: "Se sou o que sou, é mau-grado a escola, e não devido a ela" (p. 19). Termina o capítulo enaltecendo a importância da energia e do impulso vital capazes de elevar "o homem acima de si próprio e que é, ao mesmo tempo, a chave do êxito e da felicidade" (p. 25). Por fim, concretiza com o seu próprio testemunho:

Vi, não uma, nem vinte vezes, mas centenas de vezes, rapazes e raparigas obter bastante êxito na sua vida, e um êxito brilhante, sem que até os dezasseis anos tivessem seguido programas oficiais, e por terem vivido, não nos bancos das escolas, mas sim ao ar livre; por terem conhecido a livre expansão do corpo e dos seus interesses dominantes; por haverem sido postos em contacto com a verdadeira vida, e não com esses simulacros de vida conservados em bocais, nos museus, encerrados em páginas de manuais e nos armários do material de ensino das nossas escolas. (Ferrière, 1928, pp. 23-24)
Todo este tipo de discurso procura desvalorizar um modelo de educação escolarizada, cujas virtudes, aliás, não cessaram de ser valorizadas, como louvadas, ao longo do século XIX, conhecido como "educador" - a expressão é de Daniel Hameline (2000, p. 33) -, considerado medieval, ou seja, obscurantista, verbalista e autoritário. Por outras palavras, uma educação escolarizada assente no tripé da ordem, da disciplina e da autoridade, e a que, por seu lado, a Educação Nova contrapõe a trilogia "ciência, bom senso e intuição", que reúne os componentes daquilo que se pode chamar uma doutrina, entendida como "uma visão especulativa constantemente regulada pelos imperativos de uma ação para empreender e para julgar" (Hameline, Jornod, \& Belkaïd, 1995, p. 44, trad. nossa).

\section{UMA NOVIDAdE PRECEDIDA DE VÁRIAS RUTURAS}

Todo o século XIX transpõe para a educação escolarizada uma tripla crença: a crença na razão, a crença na perfectibilidade e a crença no progresso. Reina uma confiança ilimitada no poder da razão e na perfectibilidade indefinida realizada pelos progressos do espírito humano. Neste contexto, Daniel Hameline (2000) assinala aqueles pedagogos (Fröbel ou sobretudo Herbart na Alemanha, Girard na Suíça, Bain ou Spencer na Grã-Bretanha) que considera, no início do século XIX, os "construtores robustos de sistemas e confiantes no poder da razão humana, [e autores da] elaboração de uma metodologia geral de ensino, ela própria suscetível de ser ensinada, experimentada e colocada em prática de acordo com cânones rigorosos" (p. 33, trad. nossa) e refere que esta está na base da imposição da ideia de que "o ensino é uma profissão que se aprende tanto ou mais que o dom específico dado pela natureza a uma minoria de corações generosos e intuitivos" (p. 33, trad. nossa). E, segundo o 
mesmo autor, o desenvolvimento destes sistemas cria as condições favoráveis à Educação Nova:

Na primeira metade do século XX, o movimento multiforme da 'educação nova' encontra um denominador comum bastante fácil numa aversão simples e declarada por uma educação que se dirá tradicional e que não tão cómodo de precisar as caraterísticas senão alegando que ela é nociva para os educandos. (Hameline, 1989, p. 953, trad. nossa)

Mesmo na questão dos métodos ativos (Hameline et al., 1995, pp. 42-44), ainda que admitindo que o conceito de "atividade" seja discutível, a rutura não é tão linear como se pode admitir, e disso tem consciência Claparède (1933, pp. 185-198), visto que a pedagogia do século XIX, depois de Comenius (1592-1670) e de Rousseau (1712-1778), com Kant (17241804), Pestalozzi (1746-1827) ou Fröbel (17821852), não os desconhecia, como nos recordam os seguintes aforismas que consubstancializam verdades antigas: "só se aprende bem aquilo que se aprende por si mesmo"; "só podemos dizer que percebemos algo quando somos capazes de explicá-lo a outra pessoa"; e, por fim, "a mente só pode apreender o que o olho e a mão conseguiram medir previamente".

Aliás, esta questão da continuidade não passou despercebida ao próprio Adolphe Ferrière, que recorda os nomes de Rousseau, de Pestalozzi e de Fröbel como grandes percursores da pedagogia moderna, e referidos mais adiante, o que na verdade quer dizer que reconhece nas suas teorias e práticas um contributo no quadro dos métodos ativos (Ferrière, 1995, pp. 85-89). O autor cita uma passagem longa do Emílio de Rousseau, de que destacamos um pequeno extrato:

Em vez de debruçar uma criança sobre os livros, se eu o ocupo num atelier, as suas mãos trabalhando para benefício da sua mente; ele acredita que é apenas um trabalhador, ele torna-se filósofo...
Tentai ensinar à criança tudo aquilo que lhe é útil na sua idade, e vereis que todo o seu tempo estará mais que preenchido... (Ferrière, 1995, p. 87, trad. nossa)

Ferrière refere também Pestalozzi ressaltando, desde logo, a sua observação: "nenhum ser humano pode receber sua educação de um outro ser", e cita longamente as palavras de um dos seus discípulos (Marc-Antoine Julien), de que nós tão-somente selecionamos um pequeno, ainda que eloquente, extrato: "Deixai desenvolverse livremente as faculdades ou disposições primitivas de cada aluno, que revelem e pronunciem a sua verdadeira natureza" (Ferrière, 1995 , p. 88 , trad. nossa). Finalmente, Ferrière cita Fröbel, o autor de A Educação do Homem (Die Menschenerziehung - 1826), para dizer que “Todo o progresso deve provir de uma acção voluntária da própria criança" e remata: "Fröbel sublinhou criança. Nós sublinharíamos antes: acção voluntária da própria criança" (1995, p. 88, trad. nossa). E conclui a referência a estes três autores do seguinte modo: "Eis-nos na possessão de uma definição de Escola activa. É a Escola em que a actividade espontânea da criança está na base de todo o trabalho: apetite de saber, necessidade de agir e de criar são manifestas em toda a criança sadia" (Ferrière, 1995, p. 89, trad. nossa).

\section{Os PARAdoxos da EdUCAÇÃo Nova}

Os partidários da nova visão de Escola se, por um lado, admitiam a influência dos pedagogos que os antecederam, por outro lado, não se cansavam de sublinhar os defeitos da chamada Escola Tradicional para, como dissemos, melhor enaltecer as virtudes do novo modelo escolar que propunham. Daí que António Nóvoa (1995) fale, e justamente, no paradoxo da Educação Nova: "desconfiança e crença nas instituições 
escolares" (p. 30). Uma desconfiança radical face à Escola Tradicional e uma confiança sem limites, que denotava já uma mistura de crença e de racionalidade ideológica de caráter científico, nas novas propostas educativas plasmadas, como é conhecido, nos enunciados "trinta princípios" propostos por Ferrière (2015, pp. 7-20).

No entanto, não obstante toda a crença nas potencialidades regeneradoras do seu modelo de Escola Nova, não obstante toda a literatura pedagógico-científica produzida pela melhor geração pedagógica de sempre, não obstante alguns exemplos práticos de escolas novas realizados por alguns dos inovadores - veja-se, por exemplo, os casos de Faria de Vasconcelos com a sua Escola de Bierges (1912), na Bélgica, da École de l'Ermitage de Ovide Decroly (1907), nos arredores de Bruxelas, e a Casa dei Bambini fundada por Maria Montessori em Roma no ano de 1907 -, a desilusão bateu à porta do movimento da Educação Nova nos meados dos anos 30. Esta desilusão é explicada com a ascensão dos totalitarismos de vários quadrantes e, sobretudo, com a eclosão da II Guerra Mundial e depois dela, como assinala Antoine Savoye (2004, pp. 254-260), face a uma opinião pública nada compreensiva das suas práticas escolares alternativas e, especialmente, face à hostilidade dos partidários, em maioria, da Escola Tradicional, além de a Educação Nova ficar aquém, no plano da ação, daquilo que prometia no plano teórico (Bloch, 1973, pp. 99-142; Gilbert, 1986, pp. 114-122). Sobre esta desilusão, António Nóvoa (1995) escreve o seguinte:

Num certo sentido, a Educação Nova é o princípio do fim de um 'discurso escolarizante' sobre a educação das crianças. Mas é também o exacerbar da crença nas potencialidades da escola (de uma outra escola, claro). É neste paradoxo que se desenvolve todo o movimento pedagógico inovador dos anos 20. Isto é, a geração da Educação

\begin{abstract}
Nova resolve a sua 'crise de fé' na escola através de uma (re)mobilização de forças para a edificação de uma escola de tipo novo. É um desafio no qual estes homens vão esgotar todas as energias. A desilusão de meados dos anos trinta só tem paralelo nas imensas expectativas (e apostas) dos anos vinte. Nunca ninguém desconfiou tanto da escola e nunca ninguém acreditou tanto na escola como os grupos quer deram corpo e voz à Educação Nova. (p. 31)
\end{abstract}

Quando Hannah Arendt (2000) escrevia sobre a amálgama pedagógica e ideológica da Educação Nova, certamente que estaria a pensar em como conciliar perfis tão diversos como os de Maria Montessori, de Adolphe Ferrière, de Célestin Freinet, de Francisco Ferrer, de Hermann Lietz, de Paul Gheb, entre outros:

Ora, no que diz respeito à educação ela mesma, só no nosso século é que a ilusão emergente do pathos do novo produziu as suas mais sérias consequências. Em primeiro lugar, permitiu que essa mistura de modernas teorias educativas provenientes da Europa Central, e que consiste numa espantosa salgalhada de coisas com sentido e sem sentido, revolucionasse todo o sistema de educação sob a bandeira do progresso... O facto mais significativo é que, em virtude de certas teorias, boas ou más, todas as regras da saudável razão humana foram postas de parte. (pp. 27-28)

Neste contexto, vão as palavras de Jacques Ulmann (1987), que surpreendem pela sua assertividade:

A noção de 'educação nova' é, apesar ou por causa do seu sucesso, uma das mais equívocas. Desde logo porque a quase-totalidade dos seus temas se encontra em educadores bem anteriores ao século XX e mesmo ao século XIX, em seguida porque os métodos ditos novos estão longe de ser sempre concordantes. Eles constituem um vasto leque de doutrinas e de práticas que nem sempre diferem 
nos pontos secundários: uns querem suprimir o esforço do trabalho infantil enquanto outros o adotam; ou ainda determinados creem que a escola deve preparar a criança para a vida social que ela é destinada a realizar, outros encerram a infância sobre si-mesma. No entanto, a oposição dos pontos de vista pode em muito dificultar a procura de uma unidade. (pp. 178-179, trad. nossa)

Por outras palavras, a Educação Nova engloba um conjunto de propostas diversas, umas mais compagináveis que as outras (Arendt, 2000; Drouin-Hans, 1997; Ulmann, 1987), e, emergindo numa época de crise da escola enquanto lugar social da educação formal, proclama uma escola "nova" e exacerba a crença nas suas potencialidades, ao mesmo tempo que é "o princípio do fim de um 'discurso escolarizante' sobre a educação das crianças" (Nóvoa, 1995, p.27).

\section{UMA “ESCOLA NOVA" PARA INSTITUIR UMA “ERA NOVA”}

Para além da questão pedagógico-educacional, os inovadores concordavam que era necessário instituir uma "era nova" (nome da revista da "Liga internacional para a Educação Nova", em publicação desde 1922) após o cataclismo da I Guerra Mundial (1914-1918). Era unânime entre todos do movimento da Educação Nova aceitarem tudo fazer para promover a paz e refundarem a "ordem antiga" por intermédio de nova educação. $\mathrm{E}$ assim a pedagogia entrava a fundo num projeto político de inspiração que visava a transformação política e social; daí a necessidade de transformar-se a Escola - Transformons lécole (Ferrière,1928) - de acordo com o programa dos "trinta pontos" preconizados por Adolphe Ferrière (2015, pp. 7-20). Deste modo, não é por acaso que o autor advoga, nas palavras de Hameline (2000), “um verdadeiro sobressalto moral, um retorno das mentalidades educativas, uma transformação radical das estruturas sociais" (p. 18, trad. nossa) por intermédio de uma Escola Nova que fosse, na verdade, capaz de criar ruturas com o passado (ouça-se o slogan "nunca mais") de uma política de guerra e, muito particularmente, de uma educação tradicional conservadora. Daí Daniel Hameline (2000) insistir que os inovadores tudo faziam para mostrarem as diferenças irreconciliáveis entre as duas sensibilidades e o antes e o depois: "tudo, exceto ser descrito como contemporâneos dessas pessoas" (p. 19, trad. nossa).

Este tipo de educação era tido, por parte dos progressistas, como o principal responsável pelo estado de coisas, nomeadamente por ter havido uma Grande Guerra, com todas as consequências dela decorrentes e que hoje são infelizmente conhecidas, ainda que Françoise Mayeur tenha salientado que a I Guerra Mundial, embora tenha sido traumática em muitos aspetos, não engendrou grandes transformações nos sistemas educativos modernos. Além disso, refere que as mudanças acontecem, quando isso é possível, na escala de amplitude de uma geração ou mesmo de várias gerações: "A guerra de 1914 apenas teve uma influência indireta no mundo do pensamento e dos hábitos pedagógicos assentes, então, sobre sólidas instituições cuja vitória podia aparecer como uma justificação" (Mayeur, 1981, p. 11, trad. nossa).

É consensual definir os anos 20 como o período dourado da Educação Nova, os chamados "os loucos anos da pedagogia”, que, no decorrer dos anos 30 e particularmente durante e após a II Guerra Mundial, parece ter significativamente esmorecido, tal como Daniel Hameline (2000) lucidamente escreve:

Mas os anos trinta precisamente verão a deflação dos entusiasmos e o desencanto dos voluntarismos. As estruturas escolares terão mostrado a sua consistência, a sua capacidade de resistir e de 
sobreviver às intenções dos inovadores muito crédulos, muito imbuídos de uma confiança ingénua na força espontânea da sua causa. É preciso ensinar-lhes que as instituições humanas acontecem numa história mais lenta que a dos acontecimentos, e que as ideias, fossem elas justas, não guiam o mundo... O movimento da Educação Nova, apesar do imperioso desejo de demarcar-se que obsessiona os seus inspiradores, prolonga uma corrente de ideias cuja presença é percetível durante todo o século XIX. Face à história lida como uma série de ruturas fracassadas, substitui-se uma história lida como uma evolução mais genética. Nela as modificações são reais e irreversíveis, mas a amplitude das mudanças de fundo não seria percetível senão à escala de uma geração. (p. 19, trad. nossa)

Na perspetiva de François Mayeur (1981), o período áureo da Educação Nova coincidiria com o fim de um século pedagógico, o século $\mathrm{XIX}$, que, segundo ele, termina por volta do ano de 1930 face a um conjunto de acontecimentos e de circunstâncias políticas (o caso dos totalitarismos), económicas e sociais que não deixam de afetar as democracias ocidentais e concomitantemente os próprios sistemas educativos sob o signo de uma escolarização progressivamente generalizada e irreversível. Este processo de escolarização é iniciado mais particularmente a partir da segunda metade do século XVIII com o aparecimento, por exemplo, do Émile ou de L'Éducation (1762) e do Contrat Social (1762) de Jean-Jacques Rousseau, e até, em 1769, com a máquina a vapor de James Watt, que iria fundar a revolução industrial e mesmo uma revolução social.

Escreve Daniel Hameline (2000) que “é em torno de 1880, com efeito, que, no contexto de importantes mudanças económicas e sociais, se realiza o estabelecimento dos grandes sistemas escolares sob o rosto que ainda os conhecemos hoje" (p. 22, trad. nossa). Por outras palavras e resumindo, o desenvolvimento da escola de massas radica num modelo cujos pilares são praticamente fixados na segunda parte do século XIX. Não obstante esta evidência, os educadores progressistas pretendiam, ainda que utopicamente (Furter, 1966, pp. 56-57), afirmar, e se possível expandir e consolidar, um novo paradigma educacional conhecido sob o nome de Educação Nova, ou de Escola Nova.

Se a instrução se revela necessária para criar novas gerações capazes de responderem aos novos desafios, cada vez mais crescentes, colocados pelas duas primeiras revoluções industriais, a tarefa de educar torna-se ainda mais premente porquanto um "homem novo" carece de ser formado por uma geração pedagógica de inovadores, que era tida mesmo como a melhor segundo António Nóvoa (1995, p. 26), da qual se podem destacar Adolphe Ferrière (1879-1960), John Dewey (1859-1952), Ovide Decroly (1871-1932), Maria Montessori (1870-1952), Roger Cousinet (18811973), Édouard Claparède (1873-1940), Célestin Freinet (1896-1966) e George Kerschensteiner (1854-1932). É com eles que o movimento da Educação Nova conta para se construir o mais urgentemente que seja possível, ainda que tal possa parecer uma utopia: "Um mundo novo para um homem novo" (Montessori, 1996, p. 44, trad. nossa).

\section{O IMPODER Da EDUCAÇão Nova E} A NECESSIDAde da ilusão do Novo

Apesar de todo o esforço desta plêiade de pedagogos para afirmar a "novidade" das suas ideias pedagógicas e educativas, apesar de todo o seu empenho em afirmar o ideal do seu movimento pedagógico, não conseguiram oferecer, como o salienta António Nóvoa (1995), uma gramática radicalmente nova ao modelo escolar, aprofundando até algumas lógicas, como as de "estatização, profissionalização $e$ cientificação": 
A definirem a escola antiga, estes pedagogos [os da Educação Nova] traçam uma caricatura que pretende tornar mais nítidos os contornos da novidade de que se sentem portadores. Creio, no entanto, que - apesar de trazerem métodos e formas de trabalho ainda hoje profundamente inovadores - estes homens não põem em causa a gramática da escola, tal como ela se consolidou no término do século passado. Num certo sentido, podemos mesmo dizer que eles aprofundam as três lógicas anteriormente mencionadas (estatização, profissionalização e cientificação) no contexto de uma crença total nas potencialidades regeneradoras da escola. É por isso que a Educação Nova me parece mais a tradução no plano educativo de formas de agir e de pensar que estão disponíveis na sociedade da época do que a formulação de modelos educativos (e escolares) radicalmente novos. (p. 30)

Também Jean Houssaye (2014) afirma a linha de continuidade da Educação Nova na medida em que ela consagra a ideia de "criança ativa", uma ideia já "muito antiga", associada a uma pedagogia que coloca "a criança no centro":

A Educação nova designou-se durante bastante tempo Escola ativa. Só que a ideia de criança ativa é muito antiga, ela não remonta ao século XX... ela acharia as suas primeiras raízes no século XVIII e seria consagrada no início do princípio do século XX pela Educação nova. Pode-se identificar as duas etapas desta construção da criança como ator das suas aprendizagens. A primeira está ligada à filosofia sensualista que engendra uma primeira versão da aprendizagem como atividade sensorial e intelectual, que ela mesma se constrói na base da experiência. As teorias de Pestalozzi e de Fichte isso testemunham no século XVIII... A segunda etapa deve-se ao desenvolvimento da filosofia evolucionista do século XIX. (p. 94, trad. nossa)

Por seu lado, Célestin Freinet (1939) destaca- se da ideia de "novidade" e põe a nu o desgaste que afetava então os vocábulos "novo" ou "nova", preferindo empregar os adjetivos "moderno" e "moderna" apostos ao Movimento de que é fundador (o Movimento da Escola Moderna) e procurando acentuar sobretudo o fim que move e os utensílios e técnica adequados à educação numa "escola do povo":

É preciso livrar a nossa verborreia pedagógica da palavra 'novo' ou 'nova' que nos faz tanto estrago, porque isso leva a crer que procuramos a novidade antes de tudo, enquanto aquilo que nos preocupa exclusivamente é tornar mais racional, mais interessante, mais eficaz, o nosso trabalho escolar. Para este fim, empregamos os utensílios que nos parecem melhor responder às nossas necessidades, quer elas sejam antigas ou novas. Devemos mesmo dizer que desconfiamos, pelo contrário, da novidade que é excessiva e frequentemente mercantilizada e que nós sabemos captar da tradição tudo aquilo que ela contém de sabedoria, de bom senso e de adaptação ao meio e às necessidades humanas. 'Novidade' não é necessariamente uma recordação. São-nos necessários os utensílios e a técnica adequados à educação que nós queremos dar. Aí reside o único e verdadeiro problema. (pp. 354-355, trad. nossa)

Já John Dewey (1979), embora use frequentemente os termos educação "nova" e "progressiva" e assinale as suas diferenças substantivas em relação à educação "tradicional", não resiste a registar a sua "firme crença de que a questão fundamental não é de educação velha versus nova, mas de alguma coisa - seja qual for - que mereça o nome de educação" (p. 97), acrescentando que "faremos o progresso mais seguro e mais rápido se nos devotarmos a buscar o que seja educação e quais as condições a satisfazer para que seja ela uma realidade e não um nome ou uma etiqueta", e é nesse sentido que salienta "a necessidade de uma adequada filosofia 
de experiência” (p. 97), como a que explana em Experiência e Educação.

A adjetivação da Educação Nova continua hoje a ser posta em causa. Jean Houssaye (2001) coloca, a este propósito, a questão do "velho" e do "novo", assinalando a linha de continuidade em que ela se insere e, por outro lado, a atualidade das ideias que estavam em debate no início do século mas permanecem nos nossos dias:

Tem-se o hábito de dizer que a educação nova se tornou velha. O que é exato. Ela era já velha quando se construiu (antes da primeira guerra mundial) e expandida (entre as duas guerras), na medida em que se apresentava como a herdeira de toda uma tradição educativa inovadora (Sócrates, Comenius, Rousseau, Pestalozzi, etc.). Ela hoje aparece como velha, visto que as ideias que promove encontram-se no centro dos desafios, dos debates e dos combates desde há um século. Nós tivemos, portanto, todo o tempo de a ela nos habituarmos. Quer dizer que ela é agora muito velha? Quer dizer que ela é muito desconsiderada e demasiado ultrapassada? (p. 26, trad. nossa)

Por seu lado, Daniel Hameline (2001) interroga: "Nova? Disseram 'nova'?" (p. 31, trad. nossa). E relativiza a "novidade" da Educação Nova, situando-a na corrente do "novismo", entendido como reclamação e/ou proclamação do "novo", e de uma litania de ilustres "novistas", isto é, "partidários do novo":

O novismo [novellisme, no texto original] é uma constante da história da educação. Reivindicar que se faça o novo porque as coisas se passam mal é uma velha reclamação. Anunciar que se vai fazer o novo (...), é uma antiga proclamação. Os novistas [nouvellistes, no texto original] fazem, por vezes, desta antiguidade um argumento a seu favor: nós não queremos outra coisa diferente daquilo que já tinham preconizado Comenius, Montaigne... ou Sócrates. Eles podem seguramente beneficiar, ao longo dos séculos, de uma impressionante litania das autoridades que lhes dão razão. Mas os seus adversários - porque a oposição ao novismo [nouvellisme, no texto original] é, igualmente, uma outra constante da história da educação retornam, mas também deturpam, o argumento: efetivamente, aquilo que propõem a esse respeito não é novo, ao longo dos tempos que essas coisas se praticam sem que se tenha tido necessidade para as designar nem de sábias palavras, nem de efeitos de anúncio. (p. 31, trad. nossa)

As perspetivas de Jean Houssaye (2001) e de Daniel Hameline (2001) aproximam-se na ideia de contextualização da proposta da Educação Nova na história do pensamento pedagógico e da sua inserção numa linha de continuidade de procura e afirmação do Novo - e igualmente da sua contestação, como realça Hameline (2001).

\section{CONCLUS Ão}

Com este estudo, pretendemos afirmar que o movimento da Educação Nova representa uma continuidade, ainda que certamente inovadora nos planos do discurso e das suas práticas do agir, daquilo que já vinha acontecendo no plano educativo, especialmente a partir dos finais do século XVIII e ao longo do século XIX, com Rousseau (1712-1778), Pestalozzi (1746-1827), Fröbel (1782-1852), Basedow (1723-1790), Herbart (1776-1841) e Spencer (1820-1903), para mencionarmos apenas os principais, que, por sua vez, influenciaram os pedagogos artesãos da Educação Nova que estão na base da criação das futuras Escolas Novas desenhadas de acordo com os "trinta princípios" da autoria de Adolphe Ferrière (2015). É por isso ilusório, e mesmo pueril, pensar que a Educação Nova nasceu ex nihilo; ela só foi possível porque todo um caminho já tinha sido até então percorrido, não esquecendo igualmente a influência de 
Comenius (1592-1670) e de Herbart (17761841), mas também, por exemplo, de Émile Durkheim, cuja conceção sociológica muito influenciou Roger Cousinet - como, aliás, a sua obra La Vie Sociale des Enfants (1950) o reflete.

Esta ideia de continuidade é reconhecida por membros do movimento da Educação Nova e sublinhada por diversos atores, nomeadamente por Daniel Hameline (2001) e por Jean Houssaye (2001), que, no entanto, se afastam no que concerne à perspetiva subjacente às suas reflexões: Hameline introduz o -ismo, o sufixo formador de substantivos abstratos que, ao mesmo tempo que dá a ideia de doutrina ou sistema, acentua a usura do novo que se afirma quando usado isoladamente no plural (ismos) e assume um sentido pejorativo. Neste aspeto, e como acontece com todos os "ismos", a Educação Nova perder-se-ia na reacção contra a escola tradicional. Por isso, preconiza John Dewey (1979), em Experiência e Educação:

Todos os que olham para a frente em busca de um novo movimento em educação, adaptado à necessidade presente de uma nova ordem social, pensem em termos de educação e não de qualquer 'ismo', mesmo que seja "progressivismo". Isto porque, a despeito dele próprio, todo movimento, cujo pensamento e ação se conduzem em termos de qualquer "ismo", vê-se de tal modo arrastado a reagir contra outros "ismos", que acaba se sentindo por eles controlado. Os seus princípios, com efeito, de tal modo se formulam em reacção contra eles, que perdem de vista o exame construtivo e amplo das necessidades, problemas e possibilidades atuais. (pp. XVI-XVII)

Já Houssaye (2014) opta pela problematização e deixa implícito um convite ao leitor para olhar para a escola dos nossos dias e inquirir sobre as características da Escola Tradicional que se mantêm e as propostas da Educação
Nova de que a pedagogia escolar se apropriou e, utilizando como grelha de análise a proposta da Educação Nova, ver em que medida é que ela se tornou "ultrapassada" e o que se mantém ainda da ordem da novidade e merece ser trazido para a ordem do existente. Neste sentido, a Educação Nova continuará a ser uma ilusão necessária, se se pretende trazer a esperança para o horizonte da educação e da formação do "homem novo" de que carece a sociedade a construir. Esta perspetiva "progressiva" da educação (Dewey, 1979, p. 4) ilustra o potencial de fecundidade que tem a fórmula de Freinet, exibida durante muito tempo pela revista L'Éducateur: "Quando nos perguntam qual é a linha do nosso movimento, deveríamos sem dúvida responder: somos o movimento que desloca as linhas" (Araújo \& Araújo, 2007, p. 171). É desta perspetiva de "exame crítico dos seus próprios princípios fundamentais" (Dewey, 1979, p. 10) e realinhamentos necessários que carece qualquer movimento de renovação pedagógica que não se queira cristalizar em torno das suas propostas, que não podem deixar de ser datadas e formuladas na base de rejeições ou oposição a aspetos ou dimensões da pedagogia vigente à época da sua formulação.

É, na verdade, o Novo que, na sua função fundamental de contestação e projeção utópica num mundo ideal, sustenta a crítica das ideologias pedagógicas vigentes e, ao mesmo tempo, está inserido na corrente de "novidades" que o pensamento pedagógico incorporou e a que vem dando unidade, mostrando a capacidade da ideologia para dar uma identidade narrativa à comunidade dos pedagogos que advogam (e pugnam por) uma educação (como agora se diz) de qualidade. E se há que relativizar o "novo" no movimento da Educação Nova para não cair no "novismo", há que nele realçar igualmente a necessidade de construção de uma "pedagogia 
experimental" ou "científica", baseada no conhecimento (psicológico) da criança, tendo em vista a racionalização, a atratividade e a eficácia do trabalho escolar (Freinet, 1939) e a ideia de uma "educação funcional" e de uma "escola por medida" (Claparède, 1953; Ferrière, 1934b). Na verdade, a "era nova" que o movimento da Educação Nova quis abrir na escola pública consiste na renovação do ensino a partir dos novos conhecimentos aportados pela emergente psicologia da infância, pelo que, segundo Ferrière (1934b), essa "era nova" encontra-se no próprio "campo de ação" do movimento: "Pôr no seu lugar - o de simples 'meios' - os programas, métodos, horários e diversos processos prescritos nos regulamentos; subordinar estes meios a um fim constante - conservar e aumentar a potência espiritual da criança” (pp. 47-48).

\section{REFERÊNCIAS}

\section{A. Autores da Educação Nova}

Claparède, E. (1916). Psychologie de l'enfant et pédagogie expérimentale ( $6^{\mathrm{e} m}$ éd.). Paris: Libraire Kundig/Librairie Fischbacher.

Claparède, E. (1933). A educação funcional. S. Paulo: Companhia Editora Nacional.

Claparède, E. (1953). Lécole sur mesure. Neuchâtel: Delachaux et Niestlé, SA.

Cousinet, R. (1950). La vie sociale des enfants. Essai de sociologie enfantine. Paris: Éditions du Scarabée.

Dewey, J. (1979). Experiência e educação ( $3^{a}$ ed.). São Paulo: Companhia Editora Nacional.

Ferrière, A. (1928). Transformemos a escola. Apelo aos pais è às autoridades. Paris: Livraria Francesa e Estrangeira Truchy-Leroy.

Ferrière, A. (1934a). A escola activa. Porto: Editora Educação Nacional.

Ferrière, A. (1934b). A escola por medida, pelo molde do professor. Porto: Editora Educação Nacional.

Ferrière, A. (1995). Rousseau, Pestalozzi, Fröbel. In D. Hameline, A. Jornod, \& M. Belkaïd (Éds.), Lécole active. Textes fondateurs (pp. 85-89). Paris: PUF.

Ferrière, A. (2015). Prefácio. In A. Faria de Vasconcelos, Uma Escola Nova na Bélgica (pp. 7-20). Aveiro: Universidade de Aveiro.

Freinet, C. (1939). Après le Congrès de Grenoble. L'Educateur Prolétarien, 16, 353358.

Montessori, M. (1932). Pédagogie scientifique. 1 - La maison des enfants; 2 - Éducation élémentaire. Paris: Librairie Larousse.

Montessori, M. (1936). A criança. Lisboa: Portugália.

Montessori, M. (1996). Leeducation et la paix. Paris: Desclée de Brouwer.

\section{B. Autores sobre a Educação Nova}

Araújo, J. M., \& Araújo, A. F. (2007). Célestin Freinet: Trabalho, cooperação e aprendizagem. In J. Oliveira-Formosinho, M. T. Kishimoto, \& M. A. Pinazza (Orgs.), Pedagogia(s) da infância. Dialogando com o passado. Construindo o futuro (pp. 171-195). Porto Alegre: Artmed.

Bloch, M. A. (1973). Philosophie de léducation nouvelle ( $3^{\mathrm{e}}$ éd.). Paris: PUF.

Drouin-Hans, A. M. (1997). Pédagogies nouvelles et traditionnelles: Le nouveau, une valeur très ancienne. Penser l'Éducation. Philosophie de l'Éducation et Histoire des Idées Pédagogiques, 3, 7-27.

Gilbert, R. (1986). As ideias actuais em pedagogia ( $5^{\mathrm{a}}$ ed.). Lisboa: Moraes Editores. Hameline, D. (2001). Nouvelle? Vous avez dit "nouvelle"?. Cahiers Pédagogiques, 395, 3133.

Hameline, D., Jornod, A., \& Belkaïd, M. (1995). Lécole active. Textes fondateurs. Paris: PUF.

Houssaye, J. (2001). Du vieux, du neuf. Cahiers Pédagogiques, 395, 26-31. 
Houssaye, J. (2014). La pédagogie traditionnelle. Une histoire de la pédagogie. Suivi de "Petite histoire des savoirs". Paris: Editions Fabert.

Nóvoa, A. (1995). Uma educação que se diz nova. In A. Candeias, A. Nóvoa, \& M. H. Figueira, Sobre a Educação Nova. Cartas de Adolfo Lima a Álvaro Viana de Lemos (19231941) (pp. 24-41). Lisboa: Educa.

Savoye, A. (2004). Léducation nouvelle en France. De son irrésistible ascension à son impossible pérennisation (1944-1970). In A. Ohayon, D. Ottavi, \& A. Savoye (Eds.), Léducation nouvelle, histoire, présence et devenir (pp. 235-269). Bern: Peter Lang.

\section{OUtros Autores}

Araújo, A. F. (1997). O "Homem Novo" no discurso pedagógico de João de Barros. Braga: IEP/CEEP/UM.

Arendt, H. (2000). A crise na educação. In H. Arendt, Quatro textos excêntricos (pp. 2153). Lisboa: Relógio D’Água.

Baczko, B. (1980). Former l'homme nouveau... Utopie et pédagogie pendant la Révolution Française. Libre, 8, 89-132.

Bloch, E. (1977). L'esprit d'utopie. Paris: Éditions Gallimard.

Furter, P. (1966). Educação e vida (6a ed.). Petrópolis: Editora Vozes.

Hameline, D. (1989). Éducation. G. L'histoire de léducation. In Encyclopaedia Universalis. Corpus 7 (pp. 952-954). Paris: Éditeur à Paris.

Hameline, D. (2000). Courants et contrecourants dans la pédagogie contemporaine. Issy-les-Moulineaux: ESF Éditeur.

Mayeur, F. (1981). De la révolution à l'école républicaine. In L. H. Parias (Dir.), Histoire générale de l'enseignement et de l'éducation en France (Tome III, pp. 11-680). Paris: Nouvelle Librairie de France.

Ricoeur, P. (s/d.). Do texto à acção. Porto: RésEditora.

Ulmann, J. (1987). La nature et l'éducation. Paris: Éditions Klincksieck.

\section{New Education and Novism in EDUCATION: ThE NEW AS NEEDED ILLUSION}

\section{Abstract}

In this article, we point out the utopian and ideological aspects of New Education educational vision, distinguishing between a totally new self-enclosed perspective, that absolutizes itself and seeks to establish a totally different world, and a relative new perspective, which recognizes parts of the novelty that are "there" waiting for a systematic formulation that recognizes and accepts them giving them the meaning of a whole. This whole is never complete and therefore unmistakable with the field of experience and open to other parts of the novelty which the whole may lack, even if it ignores it. We also discuss analytically and critically the nature of the "new" that the "newness" of New Education would be supposed to convey, and discuss whether it is not an illusion provoked by the belief and desire of the founders of New Education, a substantive and radically innovative fact as they intended to make people believe. Finally, considering the mutual exchanges between ideology and utopia as figures of the imagination and recognizing the incorporation of parts of the New into the Traditional School, we recognize the (lack of) power of New Education and reaffirm the New as a necessary illusion to renew the pedagogical movement.

KEYwORDs: Hope; New Education; Traditional School; Rupture 


\section{L'Éducation Nouvelle et Le Novellisme EN ÉDUCATION: LE NOUVEAU COMME ILLUSION NÉCESS A I RE}

\section{RÉSUMÉ}

Dans cet article, nous soulignerons les aspects utopique et idéologique de la vision éducative de l'Éducation Nouvelle tout en distinguant une perspective du totalement nouveau, qui souvre et se referme sur elle-même, s'absolutise et vise à instaurer un monde totalement autre, et une perspective du nouveau relatif, qui reconnait des aspects de la nouveauté qui sont à portée de main et prêtes pour une formulation systématique qui les accueille et leur donne le sens d'un tout, un tout pas toujours complet et, dans ce sens, incomparable avec le domaine de l'expérience et ouvert aux autres aspects de la nouveauté qui puissent lui manquer même s'il l'ignore. Nous aborderons également de façon analytique et critique la nature du "nouveau" que la "nouveauté" de l'Éducation Nouvelle devrait véhiculer et nous nous interrogerons si ce tout ne consisterait pas plus en une illusion provoquée par la croyance et par le désir des fondateurs de l'Éducation Nouvelle qu'en un facteur substantiel et radicalement novateur comme ceux-ci prétendaient le faire croire. Finalement, tenant compte des échanges mutuels de l'idéologie et de l'utopie en tant que figures de l'imagination et reconnaissant l'incorporation d'aspects du Nouveau dans l'Ecole Traditionnelle, nous identifions l'(im) pouvoir de l'Éducation Nouvelle et nous confirmerons le Nouveau comme une illusion nécessaire pour un mouvement de rénovation pédagogique.

MotS-CLÉs : Espoir ; Éducation Nouvelle ; Ecole Traditionnelle ; Rupture.

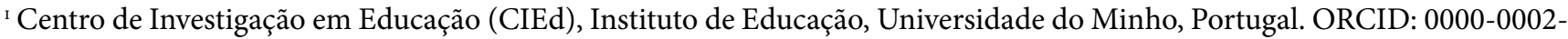
4693-8681

${ }^{\text {II } C e n t r o ~ d e ~ E s t u d o s ~ e m ~ D e s e n v o l v i m e n t o ~ H u m a n o, ~ F a c u l d a d e ~ d e ~ E d u c a c ̧ a ̃ o ~ e ~ P s i c o l o g i a, ~ U n i v e r s i d a d e ~ C a t o ́ l i c a ~ P o r t u g u e s a, ~}$ Portugal. ORCID: 0000-0003-1875-9640
} 